\title{
The Government Policy Choice in the International Regional Economic Cooperation: China-ASEAN as Instance
}

\author{
Wang Xueting \\ Beihang University, School of Management, P.R.China 100875 \\ ( tinawang1988@hss.buaa.edu.cn )
}

\begin{abstract}
In this paper, two significant government policy choices, which improve the regional economic cooperation and reduce malignant economic competition between China and Association of Southeast Asian Nations (ASEAN), are clearly presented based on dynamic game model. The first choice is adopting reward or punishment measures leading by the governments, such as financial subsidies or tax increase. The second choice is the active government promotions for the reasonable distribution of interests in the China-ASEAN international economic cooperation. Finally, as the conclusion, four specific policy suggestions and proposals for China-ASEAN nations are established around the two significant government policy choices.
\end{abstract}

Keywords: Game Model, Government Policy Intervention, China-ASEAN Regional Economic Cooperation.

\section{Introduction}

Many scholars have researched on the topic of China-ASEAN regional economic cooperation. Some scholars believe that the China and ASEAN need to further accelerate cooperation (Zhang Yinyin, Li Liming (2007) and Zhang Wenlin (2002)). Some discuss the industry trade policy between China and ASEAN (Shi Zhiyu (2003), Chen Jianjun and Xiao Chenming (2004)). Then, Some Economists point out the China-ASEAN international economic cooperation needs to strengthen the function of government and the reasonable distribution of interests (Cao Yunhua (2004) and Kuik ChengChwee (2004)), etc.. Those scholars do focus on the functions of government intervention for the China-ASEAN regional cooperation, but hardly any one uses the game model to compare and analyze the government policies in
China-ASEAN international regional cooperation. As the emphasis point, utilizing the game model, the analysis on government policy choices will be presented in this paper.

\section{The dynamic game model in the government policy intervention}

For approaching reality, the paper following will use the dynamic game model to analyze. As the government intervention policy is useful in international regional economic cooperation as many scholars mentioned. In this part, the situation with the government intervention is only considered.

Hypothesis 1: Complete information hypothesis and repeat the game with $\mathrm{N}$ times.

Hypothesis 2:Do sequential games that side $\mathrm{A}$ takes action first and then side $\mathrm{B}$ makes decision based on side A's choice. Each side can only choose cooperation or noncooperation. 
Hypothesis 3: The side A first choose the cooperative policy.

Hypothesis 4: $\sigma$ is the benefit each side gets when they do not cooperate, $a$ is the leading side's (side A) forerunner advantage, $\beta$ is the overflowing benefit after both sides cooperate, $r$ is the proportion that side $\mathrm{A}$ can gain from $\beta$. Finally, when side B does not cooperate, the $b$ is the loss of side $\mathrm{A}$ and also the extra benefit for side B itself.
Hypothesis 5: The governments of both sides make policies that give subsidies $d$ to the side which adopts cooperation and give the same punishment $d$ to the side which adopt noncooperation.

Hypothesis 6: $\sigma, \beta, a, b, r$ are all greater than zero and $r$ is unequal to 0.5 .

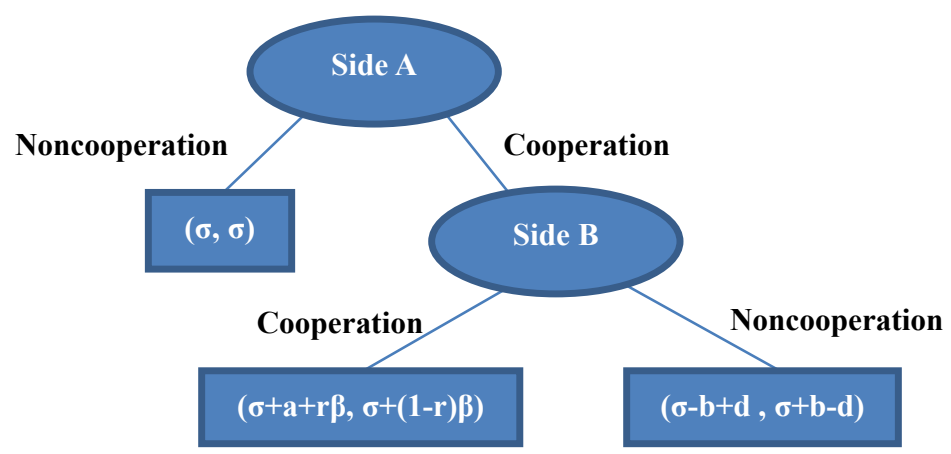

Figure 1 The dynamic game model in the government policy intervention

Based on the Hypothesis 1 to 6 and as the dynamic model shown in Figure 1, there are two kinds of situations. First, when $\sigma+(1-r) \beta>\sigma+b-d$, which means $r<1-(b-d) / \beta$, the game equilibrium result is both sides choose the policy to cooperate. It shows that if the proportion of the side A gaining from overflowing benefit is less than $1-(b-d) / \beta$, the both sides in the same international region will continue to cooperate to promote the overall regional effectiveness.

The second situation is when $r>1-(b-d) / \beta$ and $N>2$, there are two conclusions. First is that the side $\mathrm{B}$ starts with noncooperation and both sides sustain to compete, their total benefit will be $(\sigma-b+d+(N-1) \sigma, \sigma+b-d+(N-1) \sigma)$. So, in this situation, the side $\mathrm{B}$ will obtain more profit than side $\mathrm{A}$. The second is that the side $\mathrm{B}$ starts with cooperative policy and both sides last cooperation until the last time to compete, the total benefit are respectively $(\mathrm{N}-1)(\sigma+\mathrm{a}+\mathrm{r} \beta)+\sigma$ and $(\mathrm{N}-1)(\sigma+(1-\mathrm{r}) \beta)+\sigma$ for side $\mathrm{A}$ and side $\mathrm{B}$. Compared with the first conclusion, the profit for side $\mathrm{B}$ in second conclusion is decreased and the profit for side $\mathrm{A}$ is increased.

So, besides the government policy implementation, such as subsidies and punishments, the interest distribution proportion is also an important factor for government policy choice to the successful international regional cooperation.

\section{The empirical research of the government policy choice in China-ASEAN regional economic cooperation}

On one hand, the ASEAN are the largest trading partners among developing countries for China, on the other hand, China is the fourth largest trading partner for the ASEAN. On November 4, 2002, the signing of China-ASEAN Framework Agreement on Comprehensive Economic Cooperation officially launched the establishment of China-ASEAN Free Trade Area (CAFTA) process. Although the China-ASEAN regional cooperation is constantly improved, there still are some problems which hinder the development of this regional cooperation, such 
as unequal proportion of trading profits, serious

economic power, etc.

industry homogenization and imbalance nation

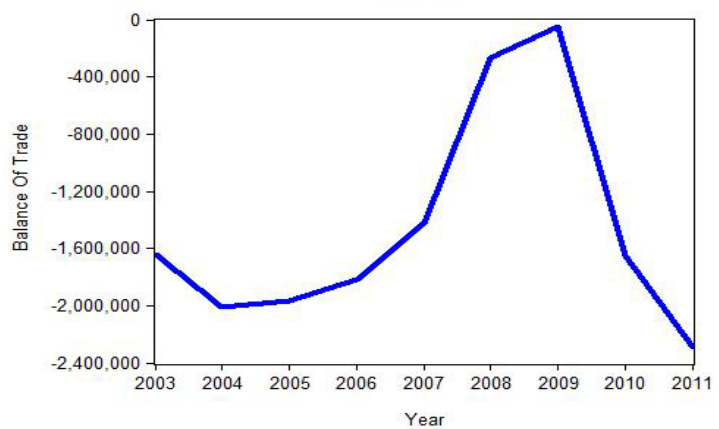

Figure 2 The balance of trade for China to ASEAN from 2003-2011 (USD) ${ }^{1}$

Balance of trade is an easy and obvious way to evaluate the distribution of interests in the international regional economic cooperation. So, Figure 2 uses the statistical data of China Statistical Yearbooks to find the unequal distribution. From Figure 2, the trade balance of China never comes above zero and during the most of the years the unbalanced situation is quite obvious except the year of 2009, which is after the world economic crisis. Among them, Malaysia, the Philippines and Thailand are the main reason for the trade deficit of China and China has always been the main reason for the trade surplus of Laos, Myanmar and Vietnam.

If this situation continues, it is hard to avoid complaining from the nations who always get trade deficit. For them, it is more likely to choose the extreme trade barriers ways to reduce the deficit in short term, because that the technology cannot fast grow and economic structure transformation cannot change by itself.

In a word, the unbalance of interest distribution for nations is not good for China-ASEAN regional economic cooperation, which is verified by empirical research. Therefore, in order to carry out long-term China-ASEAN regional economic cooperation, all the nations need to consult and establish measures and policies to support more reasonable profit distribution.

\begin{tabular}{|c|c|c|c|c|c|}
\hline \multirow{2}{*}{ Nations } & \multicolumn{5}{|c|}{ The provinces of Southwest China } \\
\cline { 2 - 6 } & Sichuan & Chongqing & Guizhou & Yunnan & Guangxi \\
\hline Singapore & $\mathbf{0 . 4 0 8}$ & 0.349 & 0.225 & 0.055 & 0.254 \\
\hline Philippines & $\mathbf{0 . 5 8 6}$ & $\mathbf{0 . 4 3 1}$ & 0.355 & 0.184 & $\mathbf{0 . 4 9 9}$ \\
\hline Vietnam & $\mathbf{0 . 8 0 3}$ & $\mathbf{0 . 5 8 4}$ & $\mathbf{0 . 5 6 5}$ & 0.278 & $\mathbf{0 . 8 1 5}$ \\
\hline
\end{tabular}

Table 1 The main manufacturing similarity coefficient between China and $\operatorname{ASEAN}^{2}$

This paper uses main manufacturing similarity coefficient to evaluate the problem of industry homogeneity in China-ASEAN regional cooperation. As Table 1 shown, the provinces of Southwest China and ASEAN have serious similarity in some main industries (Coefficient $>$ 0.4) especially for nearer and less developed nations. To solve this problem, on one hand, the nations can cooperate and consult to achieve more reasonable labor division during different industries and realize the product differentiation in order to achieve economies of scale and cost decrease. On the other hand, develop different industrial chains in one industry to enforce intra-industry trade, which gives new development space for both China and ASEAN. 


\begin{tabular}{|c|l|l|}
\hline Side B Side A & \multicolumn{1}{|c|}{ Cooperation } & \multicolumn{1}{|c|}{ Noncooperation } \\
\hline Cooperation & $\begin{array}{l}\text { (1) Set up a reasonable interest distribution } \\
\text { mechanism to cooperate and gain win-win } \\
\text { situation } \\
\text { (2) Provide the rewards and punishments } \\
\text { measures to improve cooperation } \\
\text { (3) Labor division from cooperation to realize } \\
\text { dislocation development and complementary } \\
\text { advantages }\end{array}$ & $\begin{array}{l}\text { The governments are actively } \\
\text { against the unilateral damage } \\
\text { behavior of cooperation to } \\
\text { strengthen the trust for each other }\end{array}$ \\
\hline Noncooperation & $\begin{array}{l}\text { The governments are actively against the } \\
\text { unilateral damage behavior of cooperation to } \\
\text { strengthen the trust for each other }\end{array}$ & $\begin{array}{l}\text { Compete reasonably and orderly } \\
\text { to achieve the win-win situation }\end{array}$ \\
\hline
\end{tabular}

Table 2 Game matrix for China-ASEAN government policy intervention

\section{Conclusions}

The reward and punishment measures of government policy intervention and the interest distribution for nations, which both benefit from cooperation, are two important factors to influence the international regional economic cooperation. So, in order to make the China-ASEAN regional economic cooperation develops well, all the governments inside should do the policy intervention as follows.

Firstly, establish a reasonable interest distribution mechanism for the China-ASEAN regional economic cooperation. Secondly, for the sides, which improve the China-ASEAN regional economic cooperation, the government should adopt policy intervention to encourage them by giving financial subsidies, preferential policy, etc. Thirdly, establish the constraint mechanism for every cooperation side by severely punishing the behavior of destruction to the China-ASEAN regional economic cooperation. Finally, the China-ASEAN regional economic cooperation should set up a government cooperation platform to build various kinds of cooperation methods for the sides inside the region, such as technical supports, NGO supports, personnel training supports, etc.. All those cooperation also can make the profit proportion more balanced and encourage each nation to cooperate with each other.

\section{Acknowledgement}

The authors would like to appreciate Professor Zhang $\mathrm{Li}$ for her patient guidance and meticulous explanation during this research process. Meanwhile, the author would like to thank the Editor, Associate Editors and anonymous reviewers for their constructive comments.

\section{References}

[1] Cao Yunhua. Leadership in East Asian Integration Process[J]. AROUND

SOUTHEAST ASIA, 2004(04): 4-10

[2] Chen Jianjun, Xiao Chenming. The Comparative Study on Trade

Complementarity between China and Main Countries of ASEAN [J]. World Economic Study, 2004(08): 22-28

[3] Kuik Cheng- Chwee. An Analysis of China's Interests in Involvement in the ASEN-Led Regional Regimes [J]. World Economics and Politic, 2004(09):53-59

[4] Shi Zhiyu. Intra- Industry Trade: China and ASEAN Countries. [J]. World Economic Papers, 2003(04):37-43

[5] Zhang Yunlin. East Asia cooperation and the construction of CAFTA. [J]. Journal of Contemporary Asia-Pacific Studies, 2002(01):6-11 
[6] Zhang Yinyin, Min Xiaoying \& Li Limin. On the Similarities in Industrial Mechanism between Southwest of China and Nations of ASEAN- Taking Manufacture as Instance [J]. AROUND SOUTHEAST ASIA, 2007(07): 16-20

1 The data are from the China Statistical Yearbook during the year of 2004 to 2012. http://www.stats.gov.cn/tjsj/ndsj/

${ }^{2}$ The data are from Zhang yinyin, Min Xiaoying \& Li Limin. On the Similarities in Industrial Mechanism between Southwest of China and Nations of ASEAN- Taking Manufacture as Instance [J]. AROUND SOUTHEAST ASIA ,2007(07):16-20 